\title{
Acupoint Application for Asthma Therapy in Adults: A Systematic Review and Meta-Analysis of Randomized Controlled Trials
}

\author{
$\mathrm{Li} \mathrm{Su}^{\mathrm{a}}$ Ling Meng ${ }^{\mathrm{b}}$ Ran Chen ${ }^{\mathrm{b}}$ Weihua Wu ${ }^{\mathrm{b}}$ Bo Peng ${ }^{\mathrm{c}}$ Lixin Man ${ }^{\mathrm{d}}$ \\ a Second Department of Cadre, Jinan Military General Hospital, Jinan, Shandong, China; \\ b Department of Respiration, Affiliated Hospital of Taishan Medical University, Taian, Shandong, China; \\ cTianjin University of Traditional Chinese Medicine, Tianjin, China; \\ dDepartment of Pediatrics, Jinan Military General Hospital, Jinan, Shandong, China
}

\section{Keywords}

Acupoint application $\cdot$ Asthma $\cdot$ Meta-analysis $\cdot$ RCTs

\section{Summary}

Background: To evaluate the evidence available on the effects of acupuncture point (acupoint) application for asthma therapy in adults. Methods: Six electronic databases were searched up to May 2014 to identify relevant studies. Randomized controlled trials, which assessed the effects of acupoint application for asthma treatment in adults, were included in our review. The methodological quality of eligible studies was assessed by the Cochrane Collaboration's tool. The standardized mean difference (SMD) and 95\% confidence intervals $(\mathrm{Cl})$ of a random-effects model were calculated. The heterogeneity was assessed using $\left.\right|^{2}$ statistics. Results: Eight studies were included in our review. The aggregated results indicated that acupoint application improved forced expiratory volume in 1 second (FEV1) (SMD, $0.32 ; 95 \% \mathrm{Cl} 0.04-0.60 ; \mathrm{p}=0.03), \mathrm{FEV} 1 /$ forced vital capacity (SMD, 0.89; 95\% Cl 0.70-1.09; $\mathrm{p}<0.00001$ ), interleukin (SMD, $-0.26 ; 95 \% \mathrm{Cl}-0.50$ to $-0.01 ; \mathrm{p}=0.04)$ and immunoglobulin $\mathrm{E}$ (SMD, $-0.49 ; 95 \% \mathrm{Cl}-0.83$ to $-0.16 ; \mathrm{p}=0.004$ ) in patients with asthma, but not eosinophilic cation protein (SMD, -0.58 ; $95 \% \mathrm{Cl}-1.42$ to $0.26 ; \mathrm{p}=0.18$ ). There was no sufficient evidence for the follow-up effects of acupoint application for asthma therapy in adults. Conclusions: Acupoint application may be a valid complementary and alternative therapy for asthma in adults. It contributes especially to improving pulmonary function and reducing the levels of interleukin and immunoglobulin E. However, more studies with longer follow-ups are warranted to confirm the current findings.

(c) 2016 S. Karger GmbH, Freiburg

\author{
Schlüsselwörter \\ Akupukt-Anwendung $\cdot$ Asthma $\cdot$ Meta-Analyse $\cdot$ RCTs
}

\section{Zusammenfassung}

Hintergrund: In dieser Studie wird die bestehende Evidenzlage zur Wirkung von Akupunkt-Anwendungen bei Asthma im Erwachsenenalter evaluiert. Methodik: Sechs elektronische Datenbanken wurden bis Mai 2014 auf relevante Studien hin durchsucht. In die Studie eingeschlossen wurden randomisierte, kontrollierte Studien zur Wirkung von Akupunkt-Anwendungen bei erwachsenen Asthmapatienten. Die methodische Qualität der ausgewählten Studien wurde mithilfe des Cochrane Collaboration Tools überprüft. Die standardisierte Mittelwertdifferenz (SMD) sowie die 95\%Konfidenzintervalle (KI) eines Random-Effect-Modells wurden ermittelt. Die Heterogenität wurde durch $\mathrm{I}^{2}$-Statistiken errechnet. Ergebnisse: Insgesamt wurden acht Studien in unsere Analyse eingeschlossen. Die kumulierten Ergebnisse ergaben, dass die Akupunkt-Anwendungen die Einsekundenkapazität (FEV1) (SMD, 0,32; 95\%-KI 0,04-0,60; $p=0,03$ ) sowie FEV1/forcierte Vitalkapazität (SMD, 0,89; $95 \%-K I ~ 0,70-$ 1,$09 ; p<0,00001$ ), Interleukin (SMD, $-0,26 ; 95 \%-K I-0,50$ bis $-0,01 ; p=0.04)$ und Immunglobulin $E$ bei Asthmapatienten verbesserten. Dies traf jedoch nicht auf das eosinophile kationische Protein zu (SMD, $-0,58 ; 95 \%-K I-1,42$ bis 0,$26 ; p=$ $0,18)$. Die Evidenz für nachhaltige Effekte von AkupunktAnwendungen in der Therapie von Asthmapatienten ist nicht hinreichend. Schlussfolgerungen: Akupunkt-Anwendungen können eine sinnvolle komplementäre bzw. alternative Therapieoption bei der Behandlung von Asthma sein, vor allem zur Unterstützung der Lungenfunktion und zur Reduktion der Interleukin- und Immunglobulin-E-Level. Jedoch sind mehr Studien mit längeren Follow-ups vonnöten, um die derzeitigen Erkenntnisse zu verifizieren.

\section{KARGER \\ Fax +497614520714

\section{() 2016 S. Karger GmbH, Freiburg}

$1661-4119 / 16 / 0231-0016 \$ 39.50 / 0$
Lixin Man, MD

Department of Pediatrics

Jinan Military General Hospital

Jinan, Shandong, 250000, China

manlixin_2015@sina.com 


\section{Introduction}

Asthma is one of the most widespread chronic respiratory diseases, affecting approximately 300 million sufferers worldwide. Its incidence and severity have been continually increasing [1]. In China, more than 25 million adults suffer from asthma [2-4], and this number is rising sharply with the decrease of air quality.

In China, there is a long-established approach for prevention and treatment of asthma [2,3]. Acupuncture point (acupoint) treatments, based on traditional Chinese medicine (TCM) meridian theory, consist of a system of noninvasive therapeutic procedures of applying processed Chinese herbal medicine formulations to acupoints [5]. It is an important part of TCM and has been used in asthma management for thousands of years [6-9]. The probable mechanism underlying the positive impact of this method may be rooted in the comprehensive efficacy of both acupoint stimulation and drug action. A specific herbal preparation, processed herbal mixture with $2 \mathrm{~cm}$ in diameter which was fixed onto precisely selected acupoints (Tiantu 'CV 22', Dazhui 'CV 14', Fei Shu 'BL 13', etc.), was employed in the trials included in our review. The herbal mixture was composed of fine herbal powders (Ding Xiang 'Flos Caryophylli', Rou Gui 'Cortex Cinnamomi', Wu Zhu Yu 'Fructus Evodiae', etc.) combined with ginger juice [10]. Although the effects of acupoint herbal application for asthma therapy in adults have been reported in some studies, the role of this approach remains controversial [11-13]. Furthermore, most previous reviews were only qualitative.

Therefore, in this paper, we assessed the existing evidence on the therapeutic effects of acupoint application in the treatment of asthma in adults. In this review, meta-analyses on the influence of this traditional technique on the pulmonary functions in asthmatic patients and the levels of relevant immunological markers were included.

\section{Methods}

\section{Search Strategy}

The following electronic databases were searched from their inception to May 2014: PubMed, EMBASE, Cochrane Library, China Knowledge Resource Integrated Database, Wan Fang Data, and Weipu Database for Chinese Technical Periodicals. The following keywords were used: 'herbal medicine', 'herbal preparation', 'Chinese herbs', 'acupoint application', 'point application', 'asthma', and 'asthmatic'. Literature was also identified by citation tracking using reference lists from papers and internet searching. To retrieve unpublished studies, we searched dissertations and trial registrations and contacted experts in this field. There were no restrictions on publication status.

\section{Study Selection}

The studies that met the following criteria were included in our review: (1) design: randomized controlled trials (RCTs); (2) population: participants diagnosed with asthma and not younger than 18 years; (3) intervention: acupoint application; acupoint application was compared with any control intervention, which did not include acupoint application; (4) outcomes: pulmonary function and/or relevant immunological markers; no restrictions were imposed on the measurement tools, because a large variety of outcome measures were used in the studies; (5) RCTs should contain available data for the meta-analysis; (6) the publication was available in either English or Chinese.

\section{Data Extraction}

Two reviewers independently extracted data based on predefined criteria. We contacted the primary authors when relevant information was not reported. Differences were settled by discussion with reference to the original article. For crossover studies, we considered the risk for carryover effects to be prohibitive; thus, we selected only the first phase of the study. The first author and the year of the study were extracted as general information. Parameters, such as population, outcome assessments, interventions, and follow-up duration, were utilized to analyze the study characteristics. Disagreements were resolved by discussion.

\section{Risk of Bias}

The risk of bias was assessed independently by two reviewers through the Cochrane Collaboration's tool $[14,15]$. The following domains were assessed: 1) random sequence generation, 2) allocation concealment, 3) blinding of participants and personnel, 4) blinding of outcome assessment, 5) incomplete outcome data, 6) selective reporting, and 7) other bias. Every domain was classified as 'low risk of bias', 'high risk of bias', or 'unclear risk of bias'. The necessary information was supplemented by contacting the corresponding authors. Any arising difference was resolved by discussion.

Data Synthesis and Analysis

The meta-analyses were conducted using the Cochrane Collaboration's software (Review Manager Version 5.1). For continuous data, the standardized mean difference (SMD) and 95\% confidence intervals (CI) of the random-effects model were calculated for all eligible trials. $\mathrm{I}^{2}$ was used to assess statistical heterogeneity. The reviewers determined that the heterogeneity was high when the value of $\mathrm{I}^{2}$ was greater than $75 \%$. The present review mainly focuses on outcome measures, such as changes in the pulmonary functions and the levels of immunological markers after acupoint herbal application in asthmatic patients compared with the values of the respective parameters obtained as a result of the control interventions. Hence, the reviewers pooled data across all control groups $(\leq 75 \%)$. Similar intervention or control groups were combined using the formula of the Cochrane handbook for a single pair-wise comparison.

\section{Results}

\section{Literature Search}

After removing the duplicates, a total of 508 records were identified. During the preliminary screening of the titles and abstracts, 478 records were eliminated. After full-texts screening, eight RCTs were included in our meta-analysis [16-23]. Twenty-two records were excluded due to the lack of representative outcomes $(n=5)$ or the absence of available data for the meta-analyses $(n=17)$. The detailed search process is presented in figure 1 .

\section{Study Characteristics}

Eight studies with 1,083 participants (range: 60-362) were included in our review [16-23]. The study duration was from 2 to 24 weeks. The therapeutic programs were practiced in 3-48 sessions, with one session of 45 to $720 \mathrm{~min}$ duration. The control interventions included desensitization [16], conventional care (glucocorticoids, theophylline, anticholinergic agents, etc.) plus placebo [17], placebo only [18], theophylline and ketotifen [19], Chinese herbs $[20,22]$, and routine care $[21,23]$. The characteristics of all included studies are summarized in table 1.

\section{Risk of Bias}

The risk of bias in the included studies is presented in figure 2 . For random sequence generation, six studies (75\%) were consid- 
Fig. 1. Flow diagram of study selection and identification. Abbreviations: RCTs, randomized controlled trials.

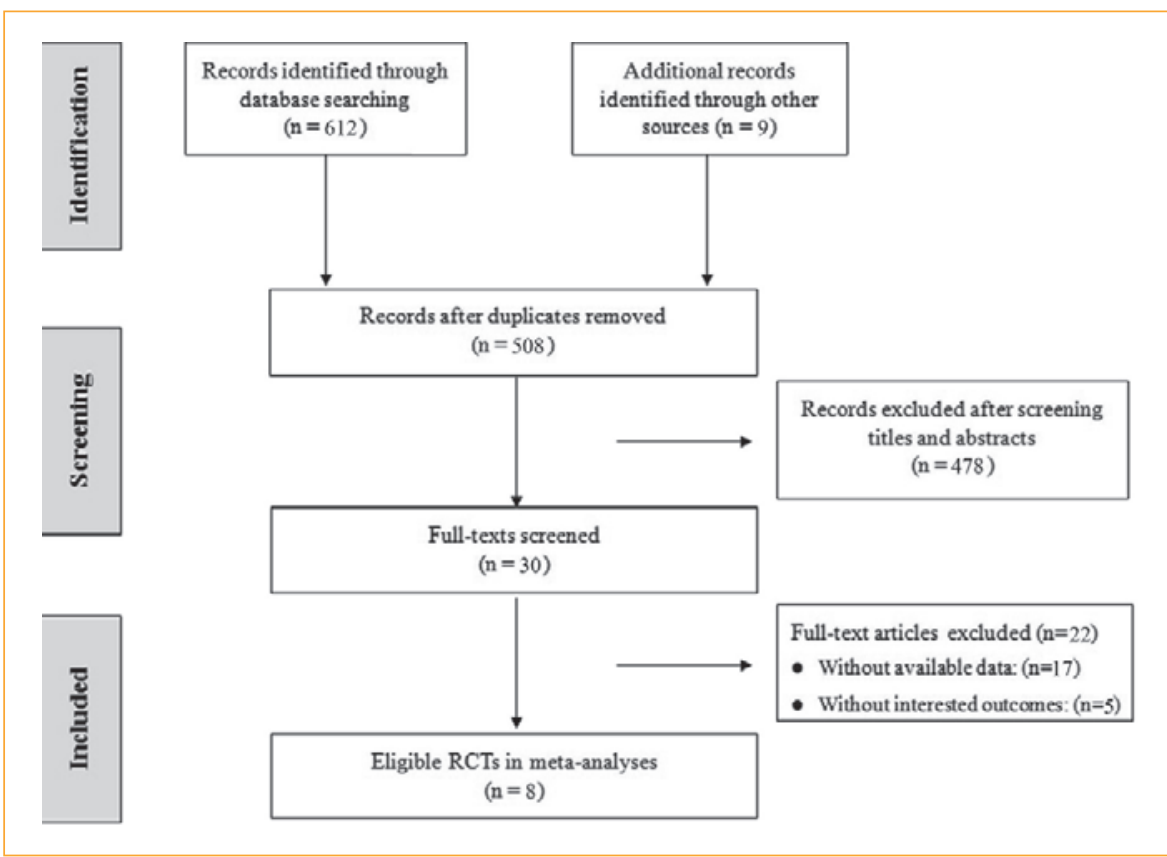

Table 1. Characteristics of the included studies

\begin{tabular}{|c|c|c|c|c|c|c|}
\hline First author, year & $\begin{array}{l}\text { Sample size, } \\
\text { mean age } \\
\text { (years) }\end{array}$ & $\begin{array}{l}\text { Follow-up } \\
\text { (weeks) }\end{array}$ & $\begin{array}{l}\text { Intervention } \\
\text { duration } \\
\text { (weeks) }\end{array}$ & $\begin{array}{l}\text { Main outcome } \\
\text { assessments }\end{array}$ & $\begin{array}{l}\text { Experimental group } \\
\text { intervention }\end{array}$ & Control group intervention \\
\hline Li 2002 [16] & 209,42 & - & 4 & IL-5,ECP & $\begin{array}{l}\text { acupoint application; } \\
\text { (4-8 h/ } 4 \text { sessions) }\end{array}$ & $\begin{array}{l}\text { desensitization treatment } \\
\text { (26 sessions) }\end{array}$ \\
\hline Mi 2005 [17] & 362,37 & 36 & 12 & FEV1/FVC & $\begin{array}{l}\text { acupoint application } \\
\text { plus usual care } \\
\text { (1 h/9 sessions) }\end{array}$ & $\begin{array}{l}\text { placebo plus usual care; } \\
\text { (1 h/ } 9 \text { sessions) }\end{array}$ \\
\hline Yаo 2007 [18] & 66,48 & - & 4 & FEV1, IL-4 & $\begin{array}{l}\text { acupoint application; } \\
\text { (4 h / } 8 \text { sessions) }\end{array}$ & $\begin{array}{l}\text { placebo } \\
\text { (4 h/ } 8 \text { sessions) }\end{array}$ \\
\hline Wang 2007 [19] & 60,37 & - & 24 & $\begin{array}{l}\text { FEV1, FVC, } \\
\text { CD } 4, \text { CD8 } \\
\text { CD4/CD8 }\end{array}$ & $\begin{array}{l}\text { acupoint application; } \\
\text { ( } 2-4 \mathrm{~h} / 48 \text { sessions })\end{array}$ & $\begin{array}{l}\text { theophylline }(0.2 \mathrm{~g}, \mathrm{Bid}) \text {; } \\
\text { ketotifen (1 } \mathrm{mg}, \mathrm{Qid})\end{array}$ \\
\hline Yang 2010 [20] & 96,33 & - & 2 & $\begin{array}{l}\text { FEV1, FVC, } \\
\text { FEV1/FVC }\end{array}$ & $\begin{array}{l}\text { acupoint application; } \\
\text { (45 min / } 7 \text { sessions) }\end{array}$ & Chinese herbs (1 dot, Qid) \\
\hline Liang 2011 [21] & 130,48 & - & 12 & ECP & $\begin{array}{l}\text { acupoint application } \\
\text { plus usual care } \\
\text { ( } 2-4 \mathrm{~h} / 12 \text { sessions) }\end{array}$ & usual care \\
\hline He 2012 [22] & 80,46 & - & 4 & $\begin{array}{l}\mathrm{IgE}, \mathrm{CD} 4, \mathrm{CD} 8 \\
\mathrm{CD} 4 / \mathrm{CD} 8\end{array}$ & $\begin{array}{l}\text { acupoint application } \\
\text { (2-6 h / } 3 \text { sessions })\end{array}$ & Chinese herbs (1 dot, Qid) \\
\hline Yuan 2012 [23] & $80, \mathrm{NR}$ & - & 4 & $\begin{array}{l}\text { FEV1, } \\
\text { FEV1/FVC }\end{array}$ & $\begin{array}{l}\text { acupoint application } \\
\text { plus usual care } \\
\text { (8-12 h / } 3 \text { sessions) }\end{array}$ & usual care \\
\hline
\end{tabular}

IL-5 = interleukin-5; ECP = eosinophilic cation protein; FEV1 = forced expiratory volume in 1 second; FVC = forced vital capacity; IL-4 = interleukin-4; $\mathrm{CD} 4=$ cluster determinant 4 ; $\mathrm{CD} 8$ = cluster determinant $8 ; \operatorname{IgE}=$ immunoglobulin $\mathrm{E} ; \mathrm{NR}=$ not reported.

ered to have a low risk of bias [17-21, 23]. Most of the included studies (75\%) were considered as carrying an unclear risk of bias in allocation concealment $[16,18,19,21-23]$. One study was categorized to have a low risk of bias in allocation concealment [17]. In blinding of participants and personnel, two trials exhibited a low risk of bias, and five studies were classified as having a high risk of bias. For the blinding of outcome assessment, four trials were con- sidered to present an unclear risk of bias [16, 19, 22, 23], and three were included in the high-risk group [17, 20, 21]. All included studies showed a low risk of bias concerning the incomplete outcome data and selective reporting [16-23]. Most of them had an unclear risk of bias in the 'other bias' category [16, 19-23]. The necessary information was provided by the corresponding authors $[17,18,20,21]$. 
Fig. 2. Risk of bias. Every domain was classified as 'low risk of bias', 'high risk of bias', or 'unclear risk of bias'.

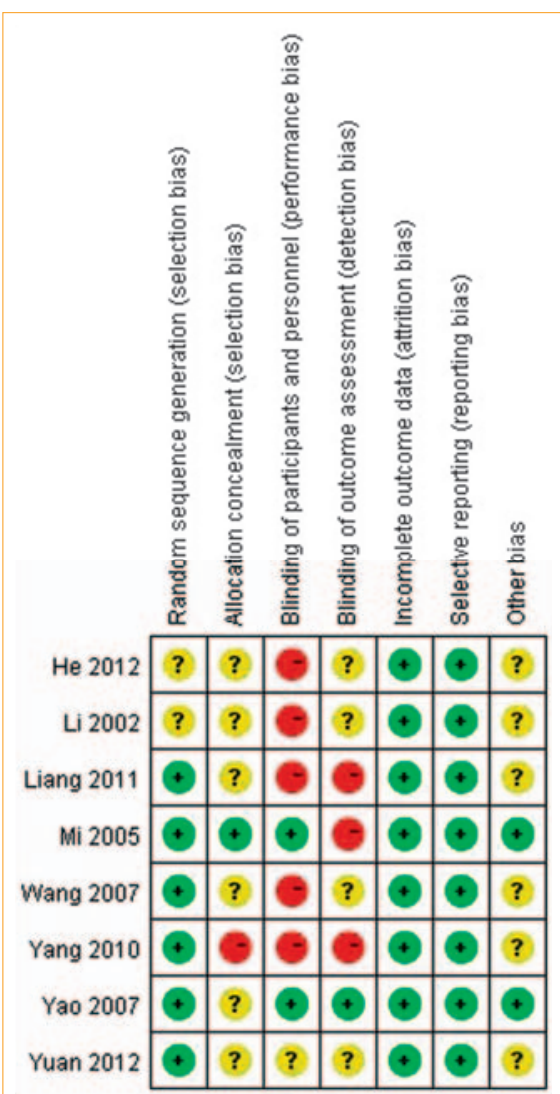

\section{Pulmonary Function}

Five studies assessed the effects of the application of herbal acupoint preparations for asthma treatment on the pulmonary functions by determination of forced vital capacity (FVC), forced expiratory volume in 1 second (FEV1), and FEV1/FVC [17-20, 23]. All studies were included in the meta-analysis. The aggregated results indicated that acupoint application improved FEV1 (SMD, 0.32; 95\% CI 0.04-0.60; $\mathrm{p}=0.03$, fig. 3) $[18-20,23]$ and FEV1/FVC (SMD, 0.89; 95\% CI 0.70-1.09; p < 0.00001, fig, 3) [17, 23].

Two studies reported the influence of acupoint application for asthma therapy on FVC values $[19,20]$. One study evaluated the action of acupoint application as compared to theophylline and ketotifen (improvements of FVC: $14.53 \%$ vs $6.94 \%$ ) [19]. The other publications reported a higher effectiveness of acupoint application versus the utilization of Chinese herbs (improvements: $2.52 \pm 1.83$ vs $2.46 \pm 2.51$ ) [20].

\section{Relevant Immunological Markers}

Five studies examined the effects of acupoint application on the levels of interleukin (IL), eosinophilic cation protein (ECP), cluster determinant 4/8 (CD4 and CD8), and immunoglobulin E (IgE) $[16,18,19,20,22]$. The aggregated results indicated that acupoint application achieved better results for the rates of IL (SMD, -0.26; $95 \%$ CI -0.50 to $-0.01 ; \mathrm{p}=0.04$, fig. 4$)[16,18]$ and IgE (SMD, $-0.49 ; 95 \% \mathrm{CI}-0.83$ to $-0.16 ; \mathrm{p}=0.004$, fig. 4) $[10,22]$ compared
Fig. 3. Forest plot showing the effect of acupoint application for asthma on pulmonary function. FEV1 = forced expiratory volume in 1 second; FVC = forced vital capacity; AA = acupoint application.



Fig. 4. Forest plot showing the effect of acupoint application for asthma on relevant immunological markers. IL = interleukin; $\operatorname{IgE}=$ immunoglobulin $\mathrm{E}$; $\mathrm{ECP}=$ eosinophilic cation protein; $\mathrm{AA}=$ acupoint application.

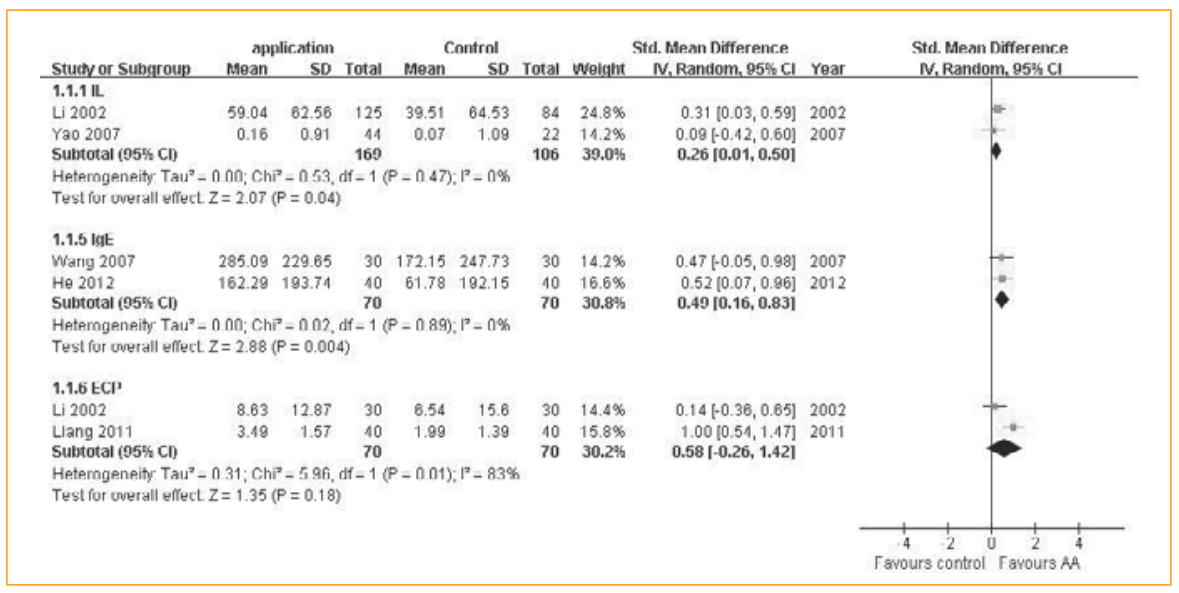


with the control interventions, but no positive effects were established regarding ECP levels (SMD, $-0.58 ; 95 \% \mathrm{CI}-1.42$ to $0.26 ; \mathrm{p}=$ 0.18 , fig. 4) $[16,21]$.

Two of the reports examined the effects of acupoint application on CD4 and CD8 levels $[19,22]$. One of them compared the influence of acupoint application with that of Chinese herbs (improvements: $8.79 \%$ vs $2.44 \%$ on CD $4 ;-9.10 \%$ vs $-3.92 \%$ on CD8) [22]. The other study assessed the effectiveness of acupoint application versus the impact exerted by theophylline and ketotifen (improvements: $-8.41 \%$ vs $-3.60 \%$ on CD $4 ; 9.61 \%$ vs $2.37 \%$ on CD 8 ) [19].

\section{Follow-up Effects}

Only one study reported follow-up effects of acupoint application and compared them with those of usual care plus placebo (improvements: $84.21 \pm 8.63$ vs $73.15 \pm 8.13$ ) after 36 weeks of follow-up [17]

\section{Discussion}

The purpose of this systematic review was to assess the evidence accumulated on the effects of acupoint application utilized for asthma treatment in adults. Current evidence demonstrates that acupoint application exerts beneficial effects in improving pulmonary function and reduces the levels of IL and IgE in patients with asthma. Nevertheless, there was no sufficient evidence to support or refute the value of acupoint application on the beneficial changes in ECP, CD4, or CD8. There was also no consistent/supportive data of the follow-up effects of acupoint application in the treatment of asthma in adults.

Acupoint application, as an alternative option in asthma therapy, was frequently reported in China. However, there were wide variations in study design, and random assignment was not used in most studies. Finally, only eight RCTs met our inclusion criteria. In our review, detailed subgroup meta-analyses were conducted based on different outcome measures. They revealed the effects of acupoint application on different symptoms of asthma. The aggregated results indicated that acupoint application improved levels of FEV1, FEV1/FVC, IL, and IgE in patients with asthma. Although some aggregated results were based on only two eligible RCTs, they provided supportive information that this alternative therapy exerted more beneficial influence on the condition of patients with asthma as compared to conventional treatment or/and placebo.

Due to the small sample size and poor methodology, there were no clear recommendations in applying TCM for the treatment of asthma [24-26], although some studies reported promising effects [27-31]. The employment of Chinese herbal preparations resulted in beneficial improvements in the pulmonary function and relieved asthma symptoms [27-29]. The mechanisms of action of acupoint application in the therapy of asthma remain unclear. Based on TCM theory, an imbalanced flow of 'Qi' can lead to chronic pul- monary disorders. The herbal mixture applied on the acupoints could regulate 'Qi' and improve pulmonary function [30, 31]. Some studies showed that acupuncture also had beneficial effects on the pulmonary function of patients with asthma [32, 33]. Carneiro et al. [34] reported that the stimulation provided by acupuncture (Fei Shu 'BL 13') could lead to the improvement of lung inflammation and cellular inflammatory processes. The acupoint approach, as a complementary and alternative therapy for asthma, is realized through the application of a processed herbal mixture to specific acupoints. Therefore, the previous studies on the utilization of Chinese herbal preparations and acupuncture for asthma treatment provided indirect evidence for the effect of acupoint application in the management of asthma.

There were several limitations in our review: (a) there were only few eligible trials in some subgroups of meta-analyses due to the strict eligibility criteria of our review. Although the aggregated results might have been biased, low eligibility criteria would generate more doubtful results. Finally, only eight RCTs were included in our review, in which the control interventions were different, and each of them had a relatively small sample size. Thus, a subgroup analysis based on different control interventions was not conducted; (b) the findings of the eligible studies in our review might have been affected by different dosing parameters of the herbal preparations for acupoint application, such as the time of each session and the total duration of the sessions; (c) most of the included studies did not report adverse events, so it was not clear whether the negative effects had been measured or not; (d) in the metaanalysis of the influence of acupoint application on ECP, the results of two trials were pooled (83\%), yet no favorable effects on ECP could be found.

\section{Conclusions}

Moderate evidence has been collected in this systematic review that acupoint application exerts beneficial effects in improving pulmonary functions and reducing IL and IgE levels in adults with asthma. There was no sufficient evidence to support or refute the value of acupoint application on ECP, CD4 nor CD8. Considering the poor methodological quality of the papers evaluated, the small sample size, and the lack of follow-up data, more high-quality RCTs with longer follow-ups are warranted to confirm the current findings.

\section{Disclosure Statement}

The authors declare that there is no conflict of interests concerning this paper. 


\section{References}

1 Lima JJ, Mohapatra S, Feng H, et al.: A polymorphism in the NPPA gene associates with asthma. Clin Exp Allergy 2008;38:1117-1123.

2 Chen YZ: Recent status of prevention and treatment of asthma in China (in Chinese). Zhonghua Er Ke Za Zh 2004;42:81-82.

3 Chen X, Lin JT. The current prevention and treatment situation of asthma in China (in Chinese). Journal of Internal Intensive Medicine 2008;14:225-226.

4 National Cooperative Group on Childhood Asthma, Institute of Environmental Health and Related Product Safety, Chinese Center for Disease Control and Prevention, and Chinese Center for Disease Control and Prevention: Third nationwide survey of childhood asthma in urban areas of China (in Chinese). Zhonghua Er Ke Za Zhi 2013;51:729-735

5 Guo CY, Li FF: A research review of traditional Chinese medicine for asthma (in Chinese). Chinese $\mathrm{Ar}-$ chives of Traditional Chinese Medicine 2015;33:691693.

6 Wang WD, Zhang NZ: A review of traditional Chinese medicine for asthma in remission stage. Henan Traditional Chinese Medicine (in Chinese). 2013;33:305307.

7 Li XM, Srivastava K: Traditional Chinese medicine for the therapy of allergic disorders. Curr Opin Otolaryngol Head Neck Surg 2006;14:191-196.

8 Li XM: Traditional Chinese herbal remedies for asthma and food allergy. J Allergy Clin Immunol 2007;120:2531.

9 Li YL: The survey of acupoint application for asthma in the last decade (in Chinese). Clin J Trad Chin Med 2008;20:88-89. (Chinese)

10 Ruan DL: Special Diagnosis and Treatment Techniques of Shanghai University of Traditional Chinese Medicine. Shanghai, Publishing House of Shanghai University of Traditional Chinese Medicine, 2006.

11 Deng PY, Zhu Y, Chen RL: A review of acupoint application for asthma (in Chinese). Journal of External Therapy of Traditional Chinese Medicine 2011;20:4547. (Chinese)

12 Guo YR, Zhu W, Zheng Y, Wei Z, Zhao TZ, Mou JG: A research review of acupoint application in the management of bronchial asthma (in Chinese). Chinese Medicine Modern Distance Education of China 2010;8:204206.
13 Wu YS, Zhang YB, Liu LY: A review of acupoint application for asthma (in Chinese). Jiangxi Journal of Traditional Chinese Medicine. 2009;40:75-7.

14 Higgins JPT, Douglas GA: Assessing risk of bias in included studies; in Julian PTH, Green S (eds): Cochrane Handbook for Systematic Reviews of Interventions. Chichester, Wiley-Blackwell, 2008, pp 187-241.

15 Higgins JP, Altman DG, Gøtzsche PC, et al.: The Cochrane Collaboration's tool for assessing risk of bias in randomized trials. BMJ 2011;343:d5928.

16 Li YM, Lai XS, Zhuang LX, Jiang GH. Affections of dialectical application on the IL-5 and ECP for the patients with allergic asthma (in Chinese). Chinese Acupuncture and Moxibustion. 2002;22:119-120.

17 Mi JP, Liu BQ, Fu WB, et al.: Clinical curative effect observation of prevention and therapeutic effect for aplication therapy on 181 patients with bronchial asthma (in Chinese). Journal of New Chinese Medicine 2005; 37:61-62.

18 Yao H, Tong J, Zhang PD, Wang Z: Affection of acupoint application on level of inflammatory cells in patients with bronchial asthma (in Chinese). Journal of Guangzhou University of Traditional Chinese Medicine 2007;24:289-291.

19 Wang LX, Shi KH, Ni W, Zhang XF: Clinical curative effect observation for Zhisou San transdermal drug on the patients with bronchial asthma (in Chinese). Shanghai Journal of Traditional Chinese Medicine 2007;41: 19-21.

20 Yang XB, Liao JF, Hu XW: Clinical curative effect observation for Chinese medicine based on Xiaoqinglong decoction with application on 96 patients with asthma (in Chinese). Lishizhen Medicine and Materia Medica Research 2010;21:1555-1556.

21 Liang YP, Wu PF, Zheng LY: Clinical observation of the change of ECP, TXB2, 6 -Keto -PGF1 $\alpha$ in patients with allergic asthma for using application therapy (in Chinese). Modern Journal of Integrated Traditional Chinese and Western Medicine. 2011;20:2126-2127.

$22 \mathrm{He}$ FL, Hu ML: Effectiveness of summary application on the immune function of patients with bronchial asthma remission (in Chinese). China Science and Technology of Chinese Medicine 2012;19:449-450.
23 Yuan NR, Kang J: Effectiveness of acupoint application with dingchuan cream on the curative effect and IL-6 for the patients with asthma (in Chinese). Shanxi Medical Journal 2012;41:252-254.

24 Clark CE, Arnold E, Lasserson TJ, Wu T: Herbal interventions for chronic asthma in adults and children: a systematic reivew and meta-analysis. Prim Care Respir J 2010;19:307-314

25 Huntley A, Ernst E: Herbal medicines for asthma: a systematic review. Thorax 2000;55:925-929.

26 McCarnev RW, Brinkhaus B, Lasserson TJ, Linde K: Acupuncture for chronic asthma. Cochrane Database Syst Rev 2004;:CD000008.

27 Hsu CH, Lu CM, Chang TT: Efficacy and safety of modified Mai-Men-Dong-Tang for treatment of allergic asthma. Pediatr Allergy Immunol 2005;16:76-81.

$28 \mathrm{Li} \mathrm{MH}$, Zhang HL, Yang BY: Effects of ginkgo leave concentrated oral liquor in treating asthma (in Chinese). Zhongguo Zhong Xi Yi Jie He Za Zhi 1997;17: 216-218. (Chinese)

29 Xu D, Xu RH: Prevention and treatment of seasonal asthmatic patients by combined invigorating kidney for preventing asthma tablets and beclomethasone dipropinate (in Chinese). Zhongguo Zhong Xi Yi Jie He Za Zhi 1997;17:721-723.

30 Jobst KA: Acupuncture in asthma and pulmonary disease: an analysis of efficacy and safety. J Altern Complem Med 1996;2:179-206.

31 Ngai SP, Hui-Chan CW, Jones AY: A short review of acupuncture and bronchial asthma-Western and Traditional Chinese Medicine concepts. Hong Kong Physiother J 2006;24:28-38.

32 Chu KA, Wu YC, Ting YM, Wang HC, Lu JY: Acupuncture therapy results in immediate bronchodilating effect in asthma patients. J Chin Med Assoc 2007;70: 265-268.

33 Han J: Observation on effect of acupuncture at Yuji (LU 10) on the pulmonary function of patients with bronchial asthma and immediate efficacy of relieving asthma (in Chinese). Zhongguo Zhen Jiu 2012;32:891894.

34 Carneiro ER, Carneito CRW, De Castro MAP, et al.: Effect of electroacupuncture on bronchial asthma induced by ovalbumin in rats. J Altern Complement Med 2005;11:127-134. 